\title{
37. Failure of Ovariectomy to Induce Pituitary Castration Reaction in Estrogen-Induced Persistent-Diestrous Rats
}

\author{
By Yasumasa ARAI \\ Section of Neuroanatomy,*) Institute of Brain Research, School \\ of Medicine, University of Tokyo \\ (Comm. by Yô K. OKADA, M.J.A., Feb. 12, 1965)
}

It is well known that gonadectomy brings about marked changes in cytological structure of the anterior pituitary in the rat (see Purves, 1961). The occurrence of castration cell is the manifestation of the gonadotrophic function of the anterior pituitary in response to the fall in the blood level of sex steroids following gonadectomy. As early as in 1932, Hohlweg and Junkmann postulated the existence of a center controlling the pituitary gonadotrophic activity in the hypothalamus, on the basis of observation that castration cells failed to occur in the anterior pituitaries transplanted to the kidney of gonadectomized rats. In recent years, the hypothesis that the feedback action of gonadal hormones is exerted upon the hypothalamic sex center has been subject to much discussion in the rat and rabbit (see Sawyer, 1964; Everett, 1964), and the possibility of a direct action of estrogen on the anterior pituitary has been pointed out (Bogdanove, 1963; Ramirez et al., 1964).

It has been reported that a majority of female rats receiving injections of increasing doses of estrogen for the first 30 days of postnatal life exhibit, after they attain maturity, vaginal smears of diestrous type continuously, vaginal cornification never taking place (Takasugi, 1952, 1956; Noumura, 1958). In these animals, the ovaries are similar in structure to those of weanling rats, neither follicles beyond the stage of antrum formation nor corpora lutea being encountered in them. Moreover, neither follicular growth nor luteinization occurs in ovarian autografts in the spleen (Takasugi, 1953; Noumura, 1958). Both the content of LH in the anterior pituitary and that of LH-releasing factor in the hypothalamus are decidedly lower in these animals than in normal female rats (Arai, 1963). Cytologic studies revealed that, in persistent-diestrous rats, gonadotrophs are completely absent in the anterior pituitary and ovariectomy does not bring about any cytological changes characteristic of ovariectomized rats (Arai, 1964).

*) Director: Prof. T. Kusama. 
In the investigation reported here, the writer attempted to study in detail the difference in response of the hypothalamo-pituitary system to ovariectomy between normal and estrogen-induced persistent-diestrous rats, changes in the pituitary cytology following ovariectomy being used as criteria.

Materials and Methods. Sixteen female rats of the Wistar strain, maintained in the Zoological Institute, University of Tokyo, were subcutaneous injections of estrone for the first 30 days of postnatal life. In 6 rats (Group 1), daily doses were $25 \mathrm{~g} \mu$ in $0.02 \mathrm{cc}$ sesame oil for the first 10 days, $50 \mu \mathrm{g}$ in $0.04 \mathrm{cc}$ oil for the middle 10 days and $100 \mu \mathrm{g}$ in $0.08 \mathrm{cc}$ oil for the last 10 days, in 5 rats (Group 2), $50 \mu \mathrm{g}$ in $0.02 \mathrm{cc}$ oil for the first 10 days, $100 \mathrm{~g} \mu$ in $0.04 \mathrm{cc}$ oil for the middle 10 days and $200 \mu \mathrm{g}$ in $0.08 \mathrm{cc}$ oil for the last 10 days, and 5 other rats (Group 3), $100 \mu \mathrm{g}$ in $0.02 \mathrm{cc}$ oil for the first 10 days, $200 \mu \mathrm{g}$ in $0.04 \mathrm{cc}$ oil for the middle 10 days and $400 \mu \mathrm{g}$ in $0.08 \mathrm{cc}$ oil for the last 10 days. Six rats given no estrone injections served as controls (Group 4). All rats were ovariectomized when they reached the age of 100 days and sacrificed 6 weeks later. At autopsy, pituitary glands and some other endocrine organs were dessected out from each animal and weighed. The pituitaries were fixed in Helly's fluid and sectioned in paraffin at $7 \mu$, and different sections of each gland were stained by the Azan, PAS and AF techniques. Differential cell counts were performed in every 5 oil immersion fields in one half of each of horizontal sections. The methods was approximately the same as that described by Rasmussen and Herrick (1921). In each anterior pituitary, 1253 cells were counted on an average. Sections of ovaries, uteri and vaginae were stained with Carazzi's hematoxylin and eosin.

Results. Until ovariectomy, 5 of 6 rats of Group 1 showed diestrous vaginal smears continuously, while the one remaining animal exhibited persistent vaginal estrus. In Group 2, all rats continued to be in diestrous state. Group 3 rats which had received daily injections of $100 \mu \mathrm{g}, 200 \mu \mathrm{g}$ and $400 \mu \mathrm{g}$ estrone for the first, second and third 10 days of postnatal life, respectively, showed persistent vaginal cornification seemingly like that in persistent-estrous rats obtained by short-term neonatal injections of estrogen or androgen. However, avaginal cornification was not abolished by ovariectomy in these animals unlike in the persistent-estrous rats. At the time of ovariectomy, ovaries of all estrogenized rats were quite atrophic and contained small follicles but neither maturing follicles nor corpora lutea.

In the anterior pituitaries of normal rats 6 weeks after ovari- 
ectomy (Group 4), peripheral and central gonadotrophs, strongly PASpositive, aniline blue-positive (in Azan preparations) and AF-negative, markedly increased in number and in size. Some of these hypertrophied cells had become vacuolated and transformed into castration cells. In ovariectomized persistent-diestrous rats (Groups 1-3), histologic changes in anterior pituitaries were decidedly less marked, gonadotrophs being seldom found. All these results accord the writer's previous findings (Arai, 1964).

Percentages of different types of cells in the anterior pituitaries

Table I. Average pituitary weights and percentages of different types of cells in the pituitaries (Azan preparations)

\begin{tabular}{rccccc}
\hline Group & $\begin{array}{c}\text { No. of } \\
\text { rats }\end{array}$ & $\begin{array}{c}\text { Wt. of pituitary } \\
(\mathrm{mg} / 100 \mathrm{~g} \text { b. wt. })\end{array}$ & $\begin{array}{c}\text { Basophil*) } \\
(\%)\end{array}$ & $\begin{array}{c}\text { Acidophil**) } \\
(\%)\end{array}$ & $\begin{array}{c}\text { Chromophobe } \\
(\%)\end{array}$ \\
\hline 1 & 6 & $2.9 \pm 0.3^{* * *)}$ & $8.72 \pm 0.79$ & $30.80 \pm 3.33$ & $59.46 \pm 4.21$ \\
2 & 5 & $2.6 \pm 0.1$ & $4.74 \pm 0.12$ & $32.21 \pm 0.12$ & $63.81 \pm 1.26$ \\
3 & 5 & $2.4 \pm 0.1$ & $3.45 \pm 0.13$ & $32.95 \pm 1.32$ & $63.13 \pm 2.61$ \\
4 & 6 & $4.2 \pm 0.2$ & $24.16 \pm 0.58$ & $26.62 \pm 0.42$ & $48.56 \pm 0.54$ \\
\hline \multirow{2}{*}{$*$ aniline blue-positive cells } & & & \\
$* * *)$ & azocarmine-positive cells and orange G-positive cells & \\
**) & standard error of the mean
\end{tabular}

Table II. Percentages of different types of cells in the anterior pituitaries (AF preparations)

\begin{tabular}{ccccc}
\hline Group & $\begin{array}{c}\text { AF-positive } \\
\text { basophil }(\%)\end{array}$ & $\begin{array}{c}\text { AF-negative } \\
\text { basophil }(\%)\end{array}$ & $\begin{array}{c}\text { Acidophil*) } \\
(\%)\end{array}$ & $\begin{array}{c}\text { Chromophobe } \\
(\%)\end{array}$ \\
\hline 1 & $2.81 \pm 0.31$ & $5.43 \pm 0.34$ & $27.64 \pm 1.31$ & $63.24 \pm 2.11$ \\
2 & $2.77 \pm 0.29$ & $1.42 \pm 0.17$ & $28.53 \pm 1.78$ & $67.52 \pm 1.79$ \\
3 & $2.42 \pm 0.24$ & $0.99 \pm 0.05$ & $27.76 \pm 1.99$ & $68.01 \pm 1.82$ \\
4 & $2.64 \pm 0.19$ & $24.05 \pm 0.92$ & $22.05 \pm 1.58$ & $49.57 \pm 2.42$ \\
\hline
\end{tabular}

*) orange $G$-positive cells

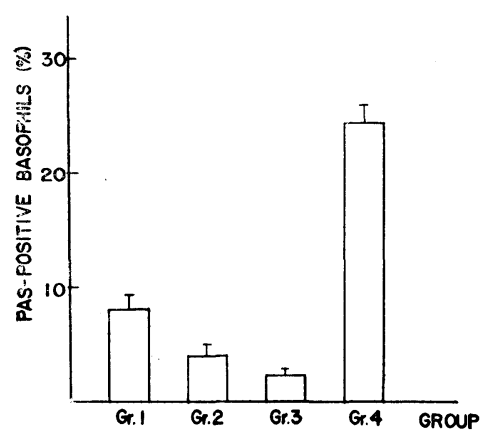

Fig. 1. Percentages of PAS-positive cells in the anterior pituitaries following ovariectomy. Vertical bar at the top of each colum shows standard error of the mean. of different groups of ovariectomized rats are presented in Table I and II, and Fig. 1. In estrogenized rats, especially in these Groups 2 and 3, aniline blue-positive (in Azan preparations) (Table I) and PAS-positive basophils (Fig. 1) were much lower in percentage than in ovariectomized controls (Group 4). In AF preparations (Table II), the numbers of AFpositive basophils, i.e. $\beta$ cells of Halmi (1950) or thyrotrophs of Purves and Griesbach (1951), were not significantly different between the control and estrogenized groups, being in- 
variably less than $3 \%$ of total pituitary cells. Therefore, it seems likely that most of the hypertrophied basophils in Azan and PAS preparations of pituitaries of the control rats (Group 4) were AFnegative basophils corresponding to $\delta$ cells of Halmi (1950) or gonadotrophs of Purves and Griesbach (1951), while a majority of basophils in Azan and PAS preparations of the glands of estrogenized rats (at least, in Groups 2 and 3) were AF-postive basophils (thyrotrophs). Among the groups of estrogenized rats, the larger were doses of estrogen administered, the smaller and the fewer were basophils in the anterior pituitaries.

Percentages of acidophils stained with azocarmine or orange $G$ in Azan preparations (Table I) or with orage $G$ in AF preparations (Table II) were slightly higher in animals of Group 3 than in those of the other groups. In all groups, chromophobes were high in percentage, although lower in the control rats than in estrogenized animals.

Discussion. The finding presented in this paper that proliferation and hypertrophy of gonadotrophs following ovariectomy were much less marked in the anterior pituitaries of persistent-diestrous rats than in normal females is consistent with the fact that in ovariectomized persistent-diestrous rats neither follicular growth nor luteinization takes place in intrasplenic ovarian autografts (Takasugi, 1953; Noumura, 1958). Both of these observations indicate that in persistent-diestrous rats, ovariectomy is not followed by any marked increase in the secretion of gonadotrophins from the anterior pituitary. Generally speaking, severity of post-ovariectomy changes in gonadotrophs in the anterior pituitary was inversely related to dose of estrogen administered neonatally. Group 3 rats given injections of the largest doses of estrogen exihibited persistent vaginal cornification seemingly like that in persistent-estrous rats secured by early postnatal injections of estrogen or androgen for a short period. However, unlike in persistent-estrous rats, the vaginal cornification was not interrupted by ovariectomy in Group 3 animals. On the other hand, in these rats, no marked changes took place in the anterior pituitaries following ovariectomy, although, in persistentestrous rats, castration cells occurred under the same condition (Arai, 1964). Therefore, Group 3 rats were persistent-diestrous rats in their real nature, persistent vaginal cornfication being a peripheral phenomenon independent of estrogenic stimulation (Takewaki, 1964).

Several workers have recently presented the hypothesis that the site of negative feedback action of estrogen in the control of secretion of pituitary gonadotrophins is in the hypothalamus. On the basis of the findings that in rats and rabbits implants of estradiol into the 
median eminence-arcuate region inhibited the development of castration cells and elavation in $\mathrm{LH}$ content of the anterior pituitaries following ovariectomy, Lisk (1963) and Kanematsu and Sawyer (1963a, b) located the focus for the negative feedback action of estrogen in the said region of the hypotahlamus. The presentf author also observed inhibition of occurrence of castration cells in the anterior pituitaries of ovariectomized rats receiving transplants of small ovarian fragments in the basal hypothalamus (Arai, 1962).

Taleisnik and McCann (1961) reported that in persistent-diestrous rats secured by placing lesions in the median eminence, ovariectomy did not produce any significant elavation in pituitary LH content. In persistent-diestrous rats used in the present investigation, the vascularization of the median eminence was left infact. Accordingly, the lack of cytological and functional changes in the anterior pituitaries of these animals following ovariectomy may be ascribed to irreversible alterations caused by neonatal estrogen treatment in the hypothalamic center controlling the pituitary gonadotrophin secretion. This conjecture is supported by the finding of the present author that the production of LH-releasing factor in the hypothalamus is markedly reduced in persistent-diestrous rats as compared with normal females (Arai, 1963).

On the basis of observations that intrapituitary estrogen depots caused disappearance of castration cells in restricted areas in proximity to the depots in the anterior pituitaries of ovariectomized rats, Bogdanove (1963) postulated direct effects of estrogen on pituitary gonadotrophs. On the other hand, Ramirez et al. (1964) who carried out similar experiments, reported that the anterior pituitary and the hypothalamus were susceptible to the effects of estrogen, although the anterior pituitary might play a less important part than the basal hypothalamus in the negative feedback action of estrogen in the control of $\mathrm{LH}$ secretion. Therefore, in estrogen-induced persistent-diestrous rats, the posibility cannot be excluded that gonadotrophs in the anterior pituitary have been irreversibly damaged by neonatal estrogen treatment.

Summary. In persistent-diestrous rats secured by daily injections of estrone for the first 30 days of postnatal life, ovariectomy did not give rise to proliferation and hypertrophy of pituitary gonadotrophs. In ovariectomized controls (Group 4), the average percentage of gonadotrophic basophils in the anterior pituitary was 24.05 \pm 0.92 . In estrogen-induced persistent-diestrous rats, the percentages were $5.43 \pm 0.34$ (Group 1), $1.42 \pm 0.17$ (Group 2) and 0.99 \pm 0.05 (Group 3), being lowered with doses of estrone administered neonatally. 
Acknowledgements, A part of the present investigation was carried out at Prof. Takewaki's laboratory in the Zoological Institute of this university. The author wishes to express his appreciation to Prof. K. Takewaki for his courtesy and invaluable advice. The author is also grateful to Prof. T. Kusama for his constant interest, encouragement and criticism.

\section{References,}

Arai, Y. (1962): Zool. Mag., 71, 333.

- (1963): Proc. Japan Acad., 39, 605.

- (1964): J. Fac. Sci. Univ. Tokyo IV, 10, 369.

Bogdanove, E.M. (1963): Endocrinology, 73, 696.

Everett, J.W. (1964): Physiol. Rev., 44, 373.

Halmi, N.S. (1950): Endocrinology, 47, 289.

Hohlweg, W., and K. Junkmann (1932): Klin. Wochenschr., 11, 321.

Kanematsu, S., and C.H. Sawyer (1963a): Endocrinology, 73, 687.

- (1963b): Am. J. Physiol., 205, 1073.

Lisk, R.D. (1963): Anat. Rec., 146, 281.

Noumura, T. (1958): J. Fac. Sci. Univ. Tokyo IV, 8, 318.

Purves, H.D. (1961): In Sex and Internal Secretions 3rd ed., ed. W.C. Young, vol. 1, p. 161, Williams and Wilkins Co., Baltimore.

W.C. Young and W.E. Griesbach (1951): Endocrinology, 55, 785.

Ramirez, V.D., R.E. Abrams, and S.M. McCann (1964): Endocrinology, 75, 243.

Rasmussen, A.T., and R. Herrick (1921): Proc. Soc. Exp. Biol. (N.Y.), 19, 416.

Sawyer, C.H. (1964): In Gonadotropins, ed. H.H. Cole, p. 113, W.H. Freeman Co., San Francisco.

Takasugi, N. (1952): Annot. Zool. Japan., 25, 337.

- (1953): Ibid., 26, 91.

- (1956): J. Fac. Sci. Univ. Tokyo IV, 7, 625.

Takewaki, K. (1964): Proc. Japan Acad., 40, 42.

Taleisnik, S., and S.M. McCann (1961): Endocrinology, 68, 263. 